\title{
Redesigning the marketing mix for eco-friendly product consumption among non-purchasers in India
}

\author{
Senthil Nathan CHOCKALINGAM \\ SRM University, Chennai Tamil, Nadu, India \\ senanmba@gmail.com \\ Densingh Joshua ISREAL \\ SRM University, Chennai Tamil, Nadu, India
}

\begin{abstract}
The present study was created in order to customise the marketing mix for nonpurchasers of eco-friendly products by studying their perspectives on the introduction of ecofriendly variants of the regular products that they are using in particular product categories (personal care and home care). Overall previous literature reviews in this area imply that there is a gap in the scientific literature on the marketing mix formulation for converting non-purchasers into purchasers of eco-friendly products to augment eco-friendly product sales and adopt green marketing. As literature reviews had clearly indicated that green purchasers have a very low percentage when compared to non-purchasers, the purpose is to create new opportunities for successful green marketing as the study tries to convert non-purchasers into purchasers. We used descriptive research design to study a sample of 885 respondents, who were surveyed in 2 cities in the Tamil Nadu state in India, to acquire an in-depth understanding of consumer behaviour that would enable the consumption of eco-friendly products among non-purchasers. The results reveal the marketing mix requirement and the eco-friendly aspects needed by the non-purchasers in order to buy the eco-friendly variants. The research sheds light on the product, price and promotion components that will attract non-purchases of eco-friendly products to buy eco-friendly products, thus facilitating green marketing mix adaptation. The study will provide valuable input for further research in formulating the marketing mix necessary to enable consumption of eco-friendly products in different geographical locations and various product categories.
\end{abstract}

Keywords: marketing mix, eco-friendly variant, non-purchasers, eco-friendly products, green marketing, eco-friendly personal care and home care products.

Please cite the article as follows: Chockalingam, S.N. and Isreal, D.J., (2016), "Redesigning the marketing mix for eco-friendly product consumption among non-purchasers in India", Management \& Marketing. Challenges for the Knowledge Society, Vol. 11, No. 1, pp. 355-370, DOI: 10.1515/mmcks-2016-0002.

\section{Introduction}

There are reliable indications that global warming has become a reality since the combined average temperature over global land and ocean surface for the year 2015 is the highest since recordkeeping began back in the 1880s. According to the National Climatic Data Center, in October 2015 we have had an average temperature across global land and ocean surfaces of $0.98^{\circ} \mathrm{C}$, above the $20^{\text {th }}$ century average, marking the sixth consecutive month a monthly global temperature record has been broken (www.ncdc.noaa.gov). Green marketing can have a significant contribution to the alleviation of the impact consumerism has on the environment by promoting the ecofriendly variants of regular products. Hence, this study aims at offering insights into the 
best way of customising the marketing mix for converting non-consumers of ecofriendly products into actual consumers, an imperative change in the present global warming scenario.

There has always been a degree of ambiguity in the usage of term 'eco-friendly

product' because the term is used differently in different contexts. The term 'organic' has been defined rather clearly, but it is used mostly for food products, and it rarely crosses to other product categories (Jeffries, 2007). In some countries the term 'green product' or 'natural product' is used for referring to eco-friendly products. Simply put, ecofriendly products contain eco-friendly ingredients whenever possible. We say a product is eco-friendly and naturally processed meaning it is not synthetic and synthetically processed. At least $90 \%$ of eco-friendly ingredients should be used, but eco-friendly does not mean 'organic' (Darrin and Smith, 2002).

As stated by Jeffries (2007), the ambiguity is amplified by the fact that there is no common worldwide industry standard for the terms 'eco-friendly', 'natural' or 'green' products. As such, one of the challenges of marketing eco-friendly products is that the term eco-friendly has never been adequately defined making it impossible for each industry to draft a common standard and certification process for the purpose of enforcement and consumer understanding. Producers of eco-friendly and organic products around the world work under different standards and regulation criteria, but they should abide by the available standards and logos in order to communicate quality (Newman, 2006). In India the term 'eco-friendly product' means a product with few chemicals, but not absolutely free of chemicals. So the term 'eco-friendly product' used throughout this research paper refers to a product having few chemicals (below $0.1 \%$ of the total ingredients) when compared to normal products with chemicals. The 'ecofriendly variant' term used refers to the eco-friendly alternatives (line extension) of normal products/brands that are available on the market.

Terms like 'phosphate free', 'recyclable', 'refillable', 'ozone friendly', and 'environmentally friendly' are some of the concepts consumers most often associate with green marketing, because these were most frequently used by green marketers in the 1990s (Polonsky, 1994). However, today, millennial consumers or the young consumers prefer terms like 'eco-friendly', 'recycled' and 'green', whereas terms like 'natural' and 'unprocessed' are not effective for communication. Also, millennials take their information from the possibility to recycle the packaging and the label in order to decide if a product is eco-friendly or not (Smith, 2010).

The eco-friendly product consumption level is low among consumers worldwide and it is experiencing a growth stage compared to normal products in all product categories (Formichelli, 2007). Thus, there arises the need to motivate non-purchasers to buy eco-friendly products to increase consumption thereby reducing the environmental impact (D'Souza et al., 2007). There have not been conducted sufficient studies on the ways in which businesses can develop their marketing strategies to motivate the non-purchaser segment to choose eco-friendly products in personal care and home care product category in a particular geographic location. According to Laroche et al. (2001), there is a large segment of undecided consumers that could be persuaded to buy eco-friendly products by the green marketers who adopt suitable marketing strategies. This segment provides market development opportunities for green marketers. This research paper offers guidelines for the customization of the marketing mix for converting non-purchasers into purchasers with respect to personal care and home care products, by measuring and analysing the preferences of non- 
MMCKS purchasers when offered an eco-friendly variant of the normal products that they regularly use.

\section{The imperative to identify the right marketing mix for non-purchasers of eco-friendly products}

In brief, green marketing is marketing with minimal detrimental impact on the environment (Uberoi, 2003). To be more exact, green marketing is best regarded as "all activities designed to generate and facilitate any exchanges intended to satisfy human needs or wants, such that the satisfaction of these needs and wants occurs with minimal detrimental impact on the natural environment"(Ottman, 1993; Davis, 1993; Kangun, 1994). By adopting green marketing strategies for personal care and home care products we can decrease the usage of harmful ingredients in product composition such as phosphates, fluoride, lead, arsenic, promote a manufacturing process based on minimal usage of resources, and encourage the usage of bio-degradable packing materials.

With their self-actualized needs satisfied, consumers are now looking for other factors of importance when purchasing goods. Rather than purchasing more and more goods, it has become fashionable to purchase items which are 'environmentally-friendly' (Maslow, 1967). According to Prothero (1990), the green movement has passed through several stages, and the second phase which we are currently experiencing is tougher on marketers because consumers have moved from light green to dark green. As a result, marketers should adopt the societal marketing concept (SMC) in such a way that they take advantage of the opportunities arising from green consumerism while being aware of the threats of the green movement so as to neutralize them and turn them into opportunities.

The major consumer barrier to purchasing green products results from concerns over not being able to assess the product's performance before purchase (Essoussi and Linton, 2010). But, if an appropriate target market is identified and a proper marketing mix is formulated, green marketing ensures sustained long-term growth with profitability for green sellers and helps gain access to new markets where the company would have a competitive advantage (Durmaz and Zengin, 2011). Studies have shown that there is a current consumer shift towards green products, but marketing strategies are still required to overcome barriers and utilize green marketing opportunities (Godelnik, 2012; National Geographic Greendex, 2012).

The study conducted by Sahasakmontri (1998) in eco-friendly personal care product category in Thailand revealed that the green aspects expected by consumers from eco-friendly personal care products were 'ingredients used' and 'not tested ion animals', and that their purchase decision was based on good value for money, product performance and skin safety level. Thus, a consumer will not pay for an eco-friendly product solely based on its green attributes; there must also be some added value to the product such as better taste, better safety, or better price. However, it appears that brand reputation matters most to people when making a green purchasing decision (Peart, 2010). According to Shrum et al. (1995) the attitude of the consumers who are willing to buy green products is related to the propensity to buy. This relationship is partially explained by gender, and by the nature of the green buying behaviour. Also, green consumers give importance to details, and advertisers should provide them with a message that is not misleading and inaccurate. Also, ads ran in printed media are preferred by green consumers rather than television because there is a relationship between green buyers and magazine reading (Zimmer et al., 1994). However, too much 
investment in advertising could lead to concerns over green washing, which is harmful not only because it misleads consumers, but also because if unscrupulous marketers continue to claim to be environmentally friendly, then companies that are true to their environmental mission, lose their competitiveness. Moreover, the problem for mainstream players when bringing organic products and promoting them was that at the same time they also brought to light the fact that their already existing brands were not organic (Vasudha, 2006). After identifying five routes to green marketing failure, Peatie and Crane (2005) concluded that a shift to green marketing requires certain changes: redefining the product, being willing to change the market, emphasising the benefits from product use, using marketing communication that aims to inform rather than just impress, focusing beyond current customer needs, being willing to manage demand and expectation, placing emphasis on cost instead of price, and taking more responsibility.

In a study of Hong Kong adolescent consumers, it was found that social influence is a major predictor of adolescent green purchasing behaviour (Lee, 2008). Green marketers should use more buzz marketing to encourage adolescent consumers to talk about environmental issues with their peers and recommend good environmental products to their friends by word of mouth in the form of face-to-face or new media communications (idem). The problem for eco-friendly or organic manufacturers is to prove that existing normal brands are not organic. According to Sireesha (2006), the best way to do this is to help consumers initiate conversations regarding eco-friendly personal care products instead of forcing them to buy certain products, because word of mouth messages can help increase customers' trust in a particular brand more than company paid advertisement.

Pro-environmental values and beliefs will result in pro-environmental behaviour. If values and beliefs are specific, product attributes will be positively perceived (PickettBaker and Ozaki, 2008). Recent climate changes have sparked an interest among green and non-traditionally green consumers to seek and demand sustainable products (Horne, 2009). Green marketing generally focuses on the efficiency of cognitive persuasion strategies, and works on the hypothesis that the consumer's high involvement concerning environmental issues is an effect of growing environmental knowledge. As the knowledge increases consumers tend to become more involved in environmental issues and to purchase green products (Hartmann and Ibanez, 2006). Consumers of green products who have positive environmental beliefs, knowledge and high involvement will exert consistent response format and commonality of intention to purchase eco-friendly products. People who know well about environmental issues such as global warming, climate change, ozone layer penetration, greenhouse gases, and toxic chemicals will be more likely to purchase eco-friendly products.

The existence of a segment of consumers who are willing to pay a premium for environmentally friendly products of sufficient size is enough to warrant the attention of marketers. But there is also a large segment of undecided consumers that may be persuaded to move into the 'willing to buy' segment through the adoption of suitable marketing mix strategies. Certain consumers are rarely influenced by claims of sustainability, but others have reported an increased willingness to pay a premium for 'green' products. Consumers do not mind paying a higher price for green products which are of high quality (Valor, 2008).

The product-related factors that are important when it comes to adopting an ecolabel include how clearly the label communicates its meaning, how well it stands out from the plethora of other labels that consumers are exposed to, and the 
MMCKS trustworthiness of the certifying and/or endorsing organization (Teisland Roe, 2005). In a study conducted on both undergraduate students and non-student respondents, it was found that among students, the attitude towards green or eco-friendly products depends on their 'commitment and efforts towards green products'. For the younger respondent group convenience is very important, if green products are more readily available and purchasing of the same product is less demanding, this group will exhibit green behaviour. Among the older group of professionals the attitude towards green marketing depended on the belief that the 'consumption of green products will reduce environmental damage' (Bahnan et al., 2011). Thus, product expectations regarding ecofriendly products differ from one consumer segment to other consumer segment as it is highlighted by previous studies.

Consumer awareness level regarding green products is high, but at the same time consumers are not aware of green initiatives taken by the government and nongovernmental organizations. The newspaper remains the leading source of communication with respect to green products. Consumers are concerned about the environment, hence marketers should develop green products and market them the same as consumer may prefer more green products over conventional products. It was found that the percentage of consumers buying green products is very low, so marketers should utilize this market opportunity by developing green products and using promotional strategies (Mayank et al., 2013). Consumers seem to be aware of environmental issues. It is expected that the government should play a vital role in the success of green products and marketing. Consumers are ready to pay extra for green products. Although we see it as everyone's responsibility to make green marketing a success, it's is difficult for all the companies to go for green marketing adaptation (Rao, 2014). Green innovation refers to the concept of environmental protection embedded into the design of the products. The second construct is green promotion also referred to as the communication that promotes the products and services. Besides promoting green advertising campaign, it should also have the necessary characteristics to enhance the corporate image of social responsibility. Thus, green innovation and green promotion are a success factor which influences the firms' performance (Hasana et al., 2015).

These findings highlight the product, price and advertising aspects necessary for augmenting eco-friendly product consumption and the fact that it is essential to focus on the undecided segment, the non-purchasing segment and convince these customers to purchase eco-friendly products (D'Souza et al., 2007). Overall studies imply that there is a gap in the scientific literature on the marketing mix formulation for converting nonpurchasers into purchasers of eco-friendly products to augment eco-friendly product sales and adopt green marketing. Though research has been done in product, price, promotion and place aspects for knowing preference and behaviours of eco-friendly product 'purchasers' there is gap for identifying marketing mix that is needed to convert 'non-purchasers segment' to 'purchasers segment' as this provides the opportunity to facilitate wider adoption of green marketing that will reduce global warming as reviews had clearly indicated that green purchasers have a very low percentage when compared to the non-purchasers.

The broad objective of this research is to identify the marketing mix elements that will attract non-purchasers of personal care and home care eco-friendly products to try and purchase eco-friendly products if present products used by them are introduced as an eco-friendly variant. The sub-objectives are to identify product, price, promotion 
expectation that will enable non-purchasers to try the eco-friendly variant of the personal care products and home care products presently used by them.

\section{Research methodology}

Constructed based on the descriptive research design paradigm, this study was based on a set of clearly formulated research questions to which it has sought to answer by applying the survey method on a large sample of respondents. Moreover, it has used the cross-sectional design method as the sample of respondents was drawn from the target population and the data was obtained at a single point in time (Malhotra and Dash, 2011).

\section{Sampling method}

The geographical area for the present research is represented by the two cities in Tamil Nadu state in India where we currently encounter the largest number of eco-friendly product retailing shops. One city is Chennai metropolitan city that is located in the northern part of Tamil Nadu and another city is Trichy that is located in the middle part of the state. The primary data for this study was collected by administering a structured questionnaire using the interview method.

The sampling method adopted for this study is purposive sampling. The sample is chosen so that a particular research purpose or objective is served and is adequate for it. The sample is typical rather than representative. Purposive sampling is similar to judgement sampling (Sekaran, 2003). The sample for this study is chosen in such a way that it should include non-purchasers who have not bought any of the eco-friendly personal care and home care products mentioned in Table 1 even though eco-friendly product retailing shops were located in their vicinity.

Prior to the main research, a pilot study was conducted on a sample of 75 city residents. To identify the non-purchasers of eco-friendly products it is essential to identify the purchasers and their locality. The retailers of eco-friendly products were interviewed for their customer location and based on the information they provided we chose to study persons living within 10-kilometre range from eco-friendly product retailers' locations. This resulted in a sample composed of respondents that were either purchasers of eco-friendly personal care and home care product so non-purchasers who do not buy eco-friendly products even though eco-friendly product retailing stores are located in their vicinity. The pilot study confirmed that the purchasers of eco-friendly products were located within a 10-kilometre range from eco-friendly products retail stores and the respondents who have not purchased even a single eco-friendly product even though eco-friendly product retailing stores were located in their vicinity were considered 'non-purchasers' for the study. Based on the findings of the pilot study we further refined the questionnaire in order to follow the research objectives and to accurately gather the required data.

\section{Questionnaire design}

The final questionnaire had two parts: questions for purchasers and questions for nonpurchasers. There were also 14 questions referring to personal information and awareness of green products that were common to all respondents. Based on their reply to the $14^{\text {th }}$ question the respondents were classified as purchasers and non-purchasers of eco-friendly personal care and home care products. The personal interview method was used to gather data from the respondents. Non-purchasers were given a set of 14 questions to elicit information that is needed for the study. This research papers focuses 
on 'non-purchasers' of eco-friendly product and finding ways of converting them into 'purchasers', so the data regarding 'purchasers' of eco-friendly product will not be discussed in the paper.

The respondents were asked questions regarding several eco-friendly product categories and they were classified as purchasers if they had purchased at least one of the eco-friendly products mentioned in Table 1 . Non-purchasers were the respondents who had not bought any of the existing eco-friendly products mentioned in Table 1.

Table 1. Product categories used in the present research

\begin{tabular}{|l|l|}
\hline No. & Product category \\
\hline & Eco-friendly personal care product category \\
\hline 1 & Eco-friendly bath soap \\
\hline 2 & Eco-friendlyshampoo \\
\hline 3 & Eco-friendly toothpaste \\
\hline 4 & Eco-friendly face wash \\
\hline & Eco-friendly home care product category \\
\hline 5 & Eco-friendly detergent \\
\hline 6 & Eco-friendly surface cleaner \\
\hline
\end{tabular}

Source: Authors' own research.

The scales used for this study for measuring marketing mix expectations such as product, price and promotion expectations have a Cronbach's coefficient alpha above 0.7,but the distribution expectation scale was not included it had a Cronbach's coefficient alpha below 0.7 (Malhotra and Dash, 2011). The study focused on 4ps of Marketing Product, Price, Place and Promotion rather than 7Ps or 9ps of marketing mix as Eco-friendly products manufacturing and consumption was in nascent stage in India during the time of this study. There is scope of further research by marketing mix formulation with 7 ps or $9 \mathrm{~s}$ after few years when the eco-friendly product manufacturing and consumption will be on large scale in India as main stream products.

\section{Description of the sample}

Out of the 885 respondents surveyed in both cities, the total number of purchasers of eco-friendly home care and personal care products was 484 and the total number of non-purchasers was 401 as shown in Table 2. The sample size surveyed in City 1 was 445 and the one in City 2 was 440 . We used the sample size calculator provided by www.surveysystem.com for a confidence level of $95 \%$ for the population size of people in City 1 and it resulted that the sample size to be surveyed that will adequately reflect the population is 384 residents. The sample size actually surveyed was 445 . Similarly for City 2 for a confidence level of $95 \%$, the sample size that will adequately reflect the population is 384 . The sample size actually surveyed for the study was 440 residents. The primary data was gathered from April to December 2014 in both cities.

Table 2. Purchaser /non-purchaser numbers in both cities

\begin{tabular}{|c|c|c|c|c|c|c|}
\hline & \multicolumn{2}{|c|}{ City 1 } & \multicolumn{2}{c|}{ City 2 } & \multicolumn{2}{c|}{ Total } \\
\hline Purchaser & 180 & $40.4 \%$ & 304 & $69.1 \%$ & 484 & $55 \%$ \\
\hline Non-purchaser & 265 & $59.6 \%$ & 136 & $30.9 \%$ & 401 & $45 \%$ \\
\hline Total & 445 & $100 \%$ & 440 & $100 \%$ & 885 & $100 \%$ \\
\hline
\end{tabular}

Source: Authors' own research. 
Table 2 shows that City 1 has the highest number of non-purchasers of ecofriendly products $(59.6 \%)$ and City 2 has the highest number of purchasers $(69.1 \%)$. Overall, the percentage of purchasers of eco-friendly products was $55 \%$ and the percentage of non-purchasers was $45 \%$.

Though the research work is done in two Indian cities with the highest number of eco-friendly product retailers, it revealed that $45 \%$ of the sample were non-purchasers. In other cities where there are less eco-friendly product retailers, the number of nonpurchasers will probably be higher. This shows the scope and imperativeness of the present research work. The findings of this study which attempts to convert nonpurchasers into purchasers could be used to formulate hypotheses and test them in other geographical locations around the world. They could also be tested with respect to any other product categories such as automobiles, the power sector, etc. The findings could prove to be valuable inputs for further research on the marketing mix and strategy formulation for enabling green marketing in other countries or globally as this topic is emergent and essential for preserving the environment.

\section{Research findings}

The demographic analysis shows that the highest number of non-purchasers surveyed belongs to the age group 39-48 (34.7\%), and the highest number of non-purchasers of eco-friendly personal care and home care products are males (52\%), whereas females represent $47.4 \%$. Most of non-purchasers are undergraduate degree holders representing 39.4\%, high school graduates represent $28.2 \%$, and post-graduates $15.5 \%$, diploma holders $15.0 \%$, Ph.D. $1.5 \%$ and others $0.5 \%$.

The Friedman test results presented in Table 3 show there is a significant difference among the intentions of non-purchasers to choose the eco-friendly variant from the product categories considered in this research, if presented with this alternative, as the significance level is less than 0.05. Table 3 shows that among the product categories toothpaste was ranked first (mean rank 4.16), detergent was ranked second (mean rank 3.51), bath soap was ranked third (3.47), shampoo was ranked fourth (3.35), surface cleaner was ranked fifth (3.29) and face wash was ranked sixth (mean rank 3.21) when considering the buying intention if presented the eco-friendly variant of the products currently used. We may conclude that the eco-friendly variant of tooth paste holds the highest buying preference when compared to the other product categories.

Table 3. Friedman test for difference among the non-purchasers' intentions to buy the eco-friendly variants of currently used products

\begin{tabular}{|c|c|c|}
\hline Buying intention & $\begin{array}{c}\text { Mean } \\
\text { rank }\end{array}$ & Rank \\
\hline Tooth paste & 4.16 & 1 \\
\hline Bath Soap & 3.47 & 3 \\
\hline Detergent & 3.51 & 2 \\
\hline Surface cleaner & 3.29 & 5 \\
\hline Shampoo & 3.35 & 4 \\
\hline Face wash & 3.21 & 6 \\
\hline \multicolumn{2}{|c|}{401} \\
\hline Chi-Square & 193.957 \\
\hline Df & 5 \\
\hline Asymp. Sig. & .000 \\
\hline
\end{tabular}

Source: Authors' own research. 
MMCKS Table 4 shows there is a significant difference among the non-purchasers' marketing mix expectations for the purchase of eco-friendly variants as the significance is less than 0.05 . We can infer that, among the marketing mix variables, product expectations are ranked first by non-purchasers when making the decision to buy the eco-friendly variants (mean rank 2.22) followed by price expectations (mean rank 1.91) and promotion expectations (mean rank 1.87).

Table 4. Friedman test for overall marketing mix expectations

\begin{tabular}{|r|c|}
\hline Overall marketing mix expectations & Mean rank \\
\hline Product & 2.22 \\
\hline Price & 1.91 \\
\hline Promotion & 1.87 \\
\hline $\mathrm{N}$ & 401 \\
\hline Chi-Square & 43.74 \\
\hline $\mathrm{Df}$ & 2 \\
\hline Asymp. Sig. & .000 \\
\hline
\end{tabular}

Source: Authors' own research.

The results in Table 5 show that under product expectations, the fact that the product should be eco-friendly, protect the environment and saves water was ranked first(mean rank 2.29)by non-purchasers when considering buying the eco-friendly variant of present products regularly used in case it is introduced by the manufacturers.

Table 5. Friedman test for product expectations

\begin{tabular}{|l|l|}
\hline Product expectation & Mean rank \\
\hline Eco-friendly - protects the environment and saves water & 2.29 \\
\hline Should yield quicker results when compared to a normal brand & 1.81 \\
\hline Should solve health problems better than a normal brand & 1.90 \\
\hline $\mathrm{N}$ & 401 \\
\hline Chi-Square & 115.043 \\
\hline $\mathrm{Df}$ & 2 \\
\hline Asymp. Sig. & .000 \\
\hline
\end{tabular}

Source: Authors' own research.

Table 6 shows that among price expectations, the one regarding the fact that nonpurchasers "will buy the eco-friendly variant even if it is a bit more expensive than the present product used"was ranked first (mean rank 4.92), followed by the one stating that, on principle, non-purchasers would pay a higher price in order to protect the environment (mean rank 4.15). 


\begin{tabular}{|l|l|}
\hline Price & $\begin{array}{l}\text { Mean } \\
\text { rank }\end{array}$ \\
\hline $\begin{array}{l}\text { Will buy if the eco-friendly variant is a bit more expensive than the } \\
\text { normal product used }\end{array}$ & 4.92 \\
\hline Will buy if eco-friendly has the same price as a normal brand & 4.09 \\
\hline $\begin{array}{l}\text { Don't mind paying a higher price if the eco-friendly variant performs } \\
\text { better than a normal brand }\end{array}$ & 3.89 \\
\hline $\begin{array}{l}\text { Don't mind paying a higher price if the eco-friendly gives more health } \\
\text { benefits when compared to a normal brand }\end{array}$ & 3.51 \\
\hline $\begin{array}{l}\text { Don't mind paying a higher price if the eco-friendly variant improves } \\
\text { my image or my family's image in society }\end{array}$ & 3.49 \\
\hline $\begin{array}{l}\text { Don't mind paying a higher price as buying an eco-friendly brand is } \\
\text { better than buying an inexpensive product that harms the } \\
\text { environment }\end{array}$ & 4.15 \\
\hline $\begin{array}{l}\text { Don't mind paying a higher price if the product has an eco-label from } \\
\text { an appropriate authority }\end{array}$ & 3.95 \\
\hline Df & 699 \\
\hline Assumed significance & 0.000 \\
\hline
\end{tabular}

Source: Authors' own research.

The results presented in Table7 show that with regards to promotion expectations the eco-friendly variant should be promoted through brand ambassadors such as sports stars, movie actors or eminent leaders, as this choice was ranked first by non-purchasers (mean rank 2.07).

Table 7. Friedman test for promotion expectation

\begin{tabular}{|l|l|}
\hline Promotion & Mean Rank \\
\hline $\begin{array}{l}\text { Should be promoted with brand ambassadors using sports star } \\
\text { or movie star or eminent leaders }\end{array}$ & 2.07 \\
\hline $\begin{array}{l}\text { Displaying in retail stores how purchase of these brands is } \\
\text { beneficial to society and saves mother earth }\end{array}$ & 2.00 \\
\hline $\begin{array}{l}\text { Information on how much pollution or global warming is } \\
\text { reduced by my purchase of eco-friendly variant. }\end{array}$ & 1.93 \\
\hline $\mathrm{N}$ & 401 \\
\hline Chi-Square & 7.770 \\
\hline $\mathrm{Df}$ & 2 \\
\hline Asymp. Sig & 0.021 \\
\hline
\end{tabular}

Source: Authors' own research.

The results in Table 8 show there is a significant difference between nonpurchasers' sales promotion reasons for the first time purchase, if they were presented with an eco-friendly variant to the products they regularly use, the significance level being less than 0.05 . When the eco-friendly variant has a discount in price, the non- 
MMCKS purchasers would initiate a first-time buy (mean rank 3.47). Although table 9 shows non-purchasers are willing to pay a bit higher price if they are presented with ecofriendly variants to the present products, for motivating them to try for the first time the eco-friendly variant, the discount in price is essential as it ranks first under sales promotion reasons.

Table 8. Friedman test for non-purchasers' sales promotion reason for first time purchase of ecofriendly variant of present products

\begin{tabular}{|l|l|}
\hline Sales promotion reason-first time purchase & Mean rank \\
\hline Discount in price of eco-friendly variant & 3.47 \\
\hline Free gifts along with eco-friendly variant & 2.79 \\
\hline Combo brand with normal brand at reduced price & 3.01 \\
\hline Free sample of eco-friendly variant along with normal product & 2.85 \\
\hline Planting a sapling for purchase of eco-friendly variant & 2.89 \\
\hline $\mathrm{N}$ & 400 \\
\hline Chi-Square & 108.195 \\
\hline $\mathrm{Df}$ & 4 \\
\hline Asymp. Sig. & .000 \\
\hline
\end{tabular}

Source: Authors' own research.

From Table 9 we can conclude that the newspaper is the most preferred means for creating awareness about eco-friendly products among non-purchasers, that is $28 \%$, education in schools and colleges is the next most preferred medium for creating awareness $27 \%$, followed by television $20 \%$, the Internet $14 \%$, mobile phones $4 \%$, ecoclub formulation $4 \%$, awareness through seminar conference and exhibition $3 \%$.

Table 9. Best method to create awareness about eco-friendly products among non-purchasers

\begin{tabular}{|l|l|l|}
\hline Method for creating awareness & Frequency & Percentage \\
\hline Education in school and Colleges & 166 & $27 \%$ \\
\hline TV & 126 & $20 \%$ \\
\hline Newspaper & 174 & $28 \%$ \\
\hline Internet & 86 & $14 \%$ \\
\hline Mobile & 24 & $4 \%$ \\
\hline Awareness through seminar conference and exhibition & 19 & $3 \%$ \\
\hline Eco-club formulation & 25 & $4 \%$ \\
\hline Total & 620 & $100 \%$ \\
\hline
\end{tabular}

Source: Authors' own research.

Table 10 implies that half of the non-purchasers want the eco-friendly variant of present products used by non-purchasers to be introduced by the manufacturer as "natural product". The majority of non-purchasers prefer the eco-friendly variant to be introduced be called natural product, that is as natural bath soap, natural shampoo, natural face wash, natural tooth paste, natural detergent and natural surface cleaner. Smaller percentages $(13.76 \%$ and $25.92 \%)$ of the non-purchasers wanted the ecofriendly variant to be introduced to be called eco-friendly bath soap, eco-friendly tooth paste or green bath soap or green Tooth paste. 
Table 10. Non-purchaser analysis on the name preference under which the eco-friendly variant should be introduced

\begin{tabular}{|l|l|l|}
\hline Name & Frequency & Percentage \\
\hline Natural product & 218 & $50 \%$ \\
\hline Eco-friendly product & 60 & $13.76 \%$ \\
\hline Green Product & 113 & $25.92 \%$ \\
\hline Bio-degradable product & 23 & $5.28 \%$ \\
\hline Organic product & 17 & $3.9 \%$ \\
\hline Unprocessed product & 5 & $1.15 \%$ \\
\hline TOTAL & 436 & 100 \\
\hline
\end{tabular}

Source: Authors' own research.

\section{Results, discussion and implications:}

We found out that non-purchasers have higher buying intentions for eco-friendly tooth paste and eco-friendly detergent if present products used by them in personal and home care category are introduced as eco-friendly variants. This finding is similar to the finding that adaptation of green marketing ensures sustained long-term growth with profitability for green marketers, helps in accessing new markets while enjoying competitive advantage found out by Zengin (2011).

The analysis on marketing mix variables shows product expectation is ranked first among non-purchasers, price expectation is ranked second and promotion expectation is ranked third when purchasing an eco-friendly variant to be introduced. In product expectation 'eco-friendly protects the environment and saves water' is ranked first (mean rank 2.29) for purchase of eco-friendly variant. Under price expectation 'Will buy if the eco-friendly variant is a bit more expensive than the normal product used' is ranked first (mean rank 1.91) by non-purchasers. This shows there is increasing willingness to pay a premium for "green" products and it confirms the finding according to which consumers do not mind higher price of green products if products are high quality as stated by Valor (2008). Though non-purchasers were found to be willing to pay a bit more expensive prices for the eco-friendly variant under price expectation, for motivating non-purchasers to try for the first time the eco-friendly variant a discount in price is essential as this is ranked first under sales promotion reasons.

Under promotion the eco-friendly variant should be promoted through brand ambassadors such as sports stars, movie actors or eminent leaders, as this choice was ranked first by non-purchasers (mean rank 2.07). For creating awareness with respect to the eco-friendly variant among non-purchasers the most preferred medium is the newspaper and education in schools and colleges. The predominant age group of this study is 39-48 this age group prefers newspaper as media, however Lee (2008) conducted a study of Hong Kong adolescent consumers which emphasised that green marketers should use more buzz marketing to encourage adolescent consumers to talk about environmental messages to their peers. They should recommend good environmental products to their friends by word-of-mouth in the form of face-to-face or new media communications. It may be concluded that the media for promotion of ecofriendly products differs from study to study based on the target audience demographic profile and geographic location there is no specific conclusion that could be arrived at, here.

A study conducted by Bahnan et al. (2011) found that for younger respondent groups convenience is very important, if green products are more readily available. If 
MMCKS purchasing of the same is less demanding this group will exhibit green behaviour. Among older group of professionals the attitude towards green marketing depends on 367 the fact that "consumption of green products will reduce environmental damage". When we compare the above finding with this study finding Product expectations of our respondents reveal that the products should be eco-friendly such as to save the earth and conserve water. This is ranked first (mean rank 2.29) among non-purchasers. Since the major age group for this study is 39-48, we may confirm that product expectation of older age groups is consistent and in line with previous studies and it differs across age groups.

The majority of non-purchasers prefer the eco-friendly variant to be introduced be called as 'natural product' that is natural bath soap, natural shampoo, natural face wash, natural tooth paste, natural detergent and natural surface cleaner. But when this find of our study is compared with studies done by Newman (2006) and Smith (2010) that showed the terms 'natural' or 'eco-friendly' are rather ambiguous as there is no common industry standard worldwide. She found that the two words 'natural' and 'unprocessed' were not effective for communication. The findings of our study regarding the name that should be used to call the eco-friendly variant differs from that of Smith's (2010) and Newman's (2006). We may conclude that the name the natural products need to be called depends on product category and vary depending on geographical location. This study shows that the non-purchasers in India would prefer the eco-friendly variant to be called: natural bath soap, natural tooth paste etc.

As stated in the study conducted by Laroche et al. (2001) there is a large segment of undecided consumers that may be moved to the willing to buy segment by adopting suitable marketing strategies. Though the two cities chosen for the study in a state in India that had the maximum number of eco-friendly product retailers, results show that the non-purchasers are $45 \%$. The non-purchasers percentage will be still higher in other geographical location where eco-friendly product retailing is low. This shows the wider scope for further research and imperativeness of the research area across geographical location globally and in different product categories. The study findings had given a new opening that by introducing eco-friendly variant in regular personal care and home care products used by non-purchasers there is scope for converting nonpurchasers into purchasers of eco-friendly variant. It had also given inputs on redesigning the product, price and promotion tools so that non-purchasers will buy the eco-friendly variant. Thus the research work had contributed to knowledge advancement in this research area.

The present manufacturers of personal care and home care products can introduce eco-friendly variants of their products as line extension strategy and explore new marketing opportunities for their products. Further research can be taken up in different geographical locations and results of this study can be tested to find out for any variations in results as consumers preferences differ based on their geographical location globally. The study also paves the way for future research by applying and testing above line extension strategy and develop marketing mix elements in other product categories such as automobile, home appliances, electronics for fine-tuning the findings of this study to convert non-purchasers into purchasers in these product categories that will culminate in augmenting the sales of green products and reduction of emissions and global warming. 


\section{Conclusion}

The redesigned marketing mix as founded by the study is in product the product expectation by non-purchasers is "product should be eco-friendly protect the environment and save water". In price the non-purchasers will buy if the eco-friendly variant is a bit more expensive than the normal product used by them.

Regarding promotion expectation is that the eco-friendly variant should be promoted through brand ambassadors such as sports stars, movie actors or eminent leaders, as this choice was ranked first by non-purchasers. For motivating non-purchasers to try for the first time the eco-friendly variant a discount in price is essential. In promotion the media that will effectively reach the non-purchasers and convince them to buy the ecofriendly variant is Newspapers. Education about eco-friendly variant should be given in schools and colleges.

This study has attempted to create a strategy of introducing eco-friendly variants of present products regularly used by non-purchasers in personal care and home care products by manufacturers and tried to formulate appropriate marketing mix elements to attract non-purchasers to buy the eco-friendly variant and convert them into purchasers. This segment provides market opportunity for successful green marketing and preserving the environment. The Non-purchasers of natural products are more in the market as highlighted by previous studies in this area. This study had tried to give a base for marketing strategy formulation to convert Non-purchasers into purchasers by redesigned marketing mix. This strategy with redesigned marketing mix could be tested and attempted in other product categories and different geographical locations in world by further researches to provide a world with less natural calamities exploring new marketing opportunity for marketers in various product categories in different industrial sectors.

\section{References}

Prothero, A. (1990), "Green Consumerism and the Societal Marketing Concept: Marketing Strategies for the 1990's", Journal of Marketing Management, Vol. 6, No. 2, pp. 87-103.

Todd, A.M. (2004), "The Aesthetic turn in green marketing", Ethics and the Environment Fall, Vol. 9, No. 2, pp. 86-102.

Mayank, B. and Amit, J. (2013), "Green marketing - A Study of consumer preferences and perceptions in India", Electronic Green Journal, Vol. 1, No. 36, pp. 1-19.

Census India (2011) available at http://www.censusindia.gov.in/pca/SearchDetails.

aspx?Id=674672 (Accessed on February 20, 2013).

Census India (2011) http://www.censusindia.gov.in/PopulationFinder/District_Master. aspx?state_code $=33$ (Accessed on February 20, 2013)

D'Souza, C, Taghian, M. and Khosla, R. (2007), "Examination of environmental beliefs and its impact on the influence of price, quality and demographic characteristics with respect to green purchase intention", Journal of Targeting, Measurement and Analysis for Marketing, Vol. 15, No. 2, pp. 69 - 78.

Darrin, D. and Smith, C. (2002),"Being green”, Global Cosmetic Industry, Vol. 170, No. 9, pp. $33-46$.

Durmazm, Y. and Zengin, S. (2011), “A Theoretical Approach To Concept of Green Marketing”, Interdisciplinary Journal Of Contemporary Research In Business, Vol. 3, No. 2, pp. 1808-1814. 
MMCKS Rahbar, E. and Wahid, N.A. (2011), "Investigation of green marketing tools' effect on consumers' purchase behavior", Emerald Group Publishing Limited, Business Strategy Series, Vol. 12, No. 2, pp. 73-83.

Godelnik, available at http://www.triplepundit.com/2012/12/sustainable-consumption -trends/ (Accessed on February 20, 2013).

Hartmann, P. and Ibáñez, V.A. (2006), "Green value added", Marketing Intelligence \& Planning, Vol. 24, No. 7, pp. 673-80.

Horne, R.E. (2009), "Limits to Labels: Role of eco-label in the assessment of product sustainability and routes to sustainable consumption", International Journal of consumer studies, Vol. 33, No. 2, pp. 175-182.

Lee, K. (2008), "Opportunities for green marketing: young consumers", Marketing Intelligence \& Planning, Vol. 26, No. 6, pp. 573-586.

Ottman, J. (1999), "Green Marketing: Opportunity for Innovation”, Electyronic Green Journal, Vol. 1, No. 10, pp. 1-3.

Johri, L.M. and Sahasakmontri, K. (1998), "Green marketing of cosmetics and toiletries in Thailand", Journal of Consumer Marketing, Vol. 15 No. 3, pp. 265-281.

Pickett-Baker, J. and Ozaki, R. (2008)," Pro-environmental products: Marketing Influence on consumer purchase decision", Journal of Consumer Marketing, Vol. 25, No. 5, pp. 281-293.

Peart, J. (2010), "Green Marketing: Making Sense of the Situation", Proceedings of The Academy of Marketing Studies, Vol. 15, No. 1, pp. 27-68.

Lee, K. (2008), "Opportunities for green marketing: young consumers", Marketing Intelligence \& Planning, Vol. 26, No. 6, pp. 573-586.

Smith, K.T. (2010), "An examination of marketing techniques that influence Millennials' perceptions of whether a product is environmentally friendly", Journal of Strategic Marketing ,Vol. 18, No. 6, pp. 437-450.

Laroche, M., Bergeron, J. and Barbaro-Forleo, G. (2001), "Targeting consumers who are willing to pay more for environmentally friendly products", Journal of Consumer Marketing, Vol. 18, No. 6, pp. 503-520.

Essoussi, L.H. and Linton, D.J. (2010), "New or recycled products: how much are consumers willing to pay?", Journal of Consumer Marketing, Vol. 27, No. 5, pp. 458-468.

Formichelli, L. (2007), “Organics Buyers: Going for the Greens”, Target Marketing, Vol. 30, No. 5, p. 62.

Maslow, A. (1967), "Metamotivation", The Humanist, May-June, pp. 82-84 .

Jeffries, N. (2007), “Green Convergence”, Global Cosmetic Industry, Vol. 175, No. 6, pp. 3644.

Malhotra, N. and Dash, S. (2011), Marketing Research: An Applied orientation, Pearson Education, New Jersey.

National Geographic, Greendex, available at http://images.nationalgeographic.com/wpf/mediacontent/file/GS NGS 2012GreendexHighlights 10July-cb1341934186.pdf (Accessed onFebruary 20, 2013).

Newman, K. (2006) "A Sustaining Natural Growth", Global Cosmetic Industry, Vol. 174, No. 4, pp. 32-36.

Coleman, L.J., Bahnan, N., Kelkar, M. and Curry, N. (2011), "Walking The Walk: How The Theory Of Reasoned Action Explains Adult And Student Intentions to go Green", Journal of Applied Business Research, Vol. 27, No. 3, pp. 101-107. 
NOAA National Climatic Data Center, State of the Climate: "Global Analysis for Annual 2011", available at http://www.ncdc.noaa.gov/sotc/global/2011/13 (Accessed on April 5, 2014).

Polonsky M.J. (1994), “An Introduction to Green Marketing”, Electronic Green Journal UCLA Library, Vol. 1, No. 2, pp. 1-10.

Shrum, L.J., McCarty, J.A. and Lowrey, T.M. (1995), "Buyer Characteristics of the Green Consumer and their Implications for Advertising Strategy" Journal of Advertising Vol. 24, No. 2, pp. 71-82.

Sireesha, M. (2006), "The Body Shop", Green Marketing (ICFAI), Chapter 11, First Edition, (pp 173).

Rao, S. (2014), "Green Marketing and Its Impact on Sustainable Development" International Journal of Innovative Technology \& Adaptive Management (IJITAM), Vol. 1, No. 5, pp. 39-45.

Suresh, K. (2006), "Green Marketing Concepts and Cases", First Edition, ICFAI University Press.

Teisl, M.F. and Roe, B. (2005), Evaluating the factors that impact the effectiveness of ecolabeling programmes, environment, information and consumer behaviour, Cheltenham, Elgar.

Uberoi, N.K. (2003), Environmental Management, Excel Books, New Delhi.

Sekaran, U. (2003), Research Methodology for business: A Skill building approach, John Wiley \& Sons Inc, Southern Illinois.

Valor, C. (2008), "Can consumers buy responsibly? Analysis and solutions for market failures", Journal of Consumer Policy, Vol. 31, No. 3, pp. 315-326.

Vasudha, A. (2006), Green \& Black's, Green Marketing (ICFAI), Chapter 14, First Edition.

Zimmer, M., Stafford, T., and Stafford, M. (1994), "Green issues: Dimensions of environmental concern”, Journal of Business Research, Vol. 30, No. 1, pp. 63-74.

Hasana, Z. and Alib, N.A. ( 2015), "The impact of green marketing strategy on the firm's performance in Malaysia", Elsevier Procedia - Social and Behavioral Sciences, Vol. 172, No. 2, pp. 463-470. 